\title{
Ayuntamiento y poder público en Monterrey. La comuna empresarial (1915-1917)*
}

\author{
Óscar Flores Torres \\ UNIVERSTDAD AUTÓNOMA DE NUEVO LÉON
}

$\mathbf{L}$ a proyección de Monterrey a nivel nacional e internacional se cia y de la influencia que mantiene en la economía y en la sociedad mexicanas una agrupación familiar - con base industrial- bastante extensa pero homogénea e identificable, comúnmente conocida como Grupo Monterrey.

En la última década ha sido motivo de comentarios y amplios debates el que una parte importante del grupo

* Una primera versión de este trabajo fue presentada en el seminario "Gobierno y política en las ciudades mexicanas, 1808-1917", México, Instituto de Investigaciones Dr. José María Luis Mora, 18-19 de septiembre de 1991. se haya mostrado "repentinamente" interesada por la obtención de altos puestos de elección popular, como son la gubernatura del estado y las alcadías del área metropolitana.

Sin embargo, esta última tendencia no es nueva en el transcurso de la historia nuevoleonesa. La Cámara Nacional de Comercio de Monterrey (CANACOM) desde su refundación en 1911 por la todopoderosa burguesía industrial operó como órgano parlamentario de asesoría y a veces de decisión del gobierno en diversas cuestiones públicas. Este organismo avanzó sobre los espacios vacíos del poder público, que abrieron los vaivenes de las corrien- 
tes revolucionarias en pugna, al punto de que la prensa de la época lo denominó "comuna empresarial".

La crisis política militar de este periodo se conjugó con el incremento de la cohesión de la elite empresarial heredada del porfiriato. Posteriormente, la concertación entre la burguesía y las facciones que se alternaron en la toma del poder tuvieron un denominador común, la domesticación de los mandos militares por la vía del apoyo económico y del asesoramiento para administrar los asuntos públicos. Cuestión que sólo podía ejercer el organismo más sólido y hegemónico en la región, edificado por la potente burguesía industrial regiomontana, la CANACOM.

He aquí su actuación entre 1915 y 1917 y las prácticas más comunes desarrolladas por los empresarios en esta época.

\section{INTRODUCCIÓN}

Con la embestida del ejército villista en el norte, la Convención ocupó efimeramente, entre diciembre de 1914 a mayo de 1915, casi todos los estados fronterizos, y toda la línea de abastecimiento hasta la propia ciudad de México. La facción carrancista hubo de replegarse a puntos estratégicos y de fácil evacuación -en caso de ser necesario- hacia el exterior del país.

En este toma y daca, los vacíos de poder se presentaron con frecuencia en zonas colindantes entre ambos ejércitos. La anarquía, la presencia de viejos caciques o grupos de poder $y / o$ la autoridad de nuevos per- sonajes emergidos de la revuelta, condicionaron el impacto de la revolución en estos espacios geográficos delimitados por causas coyunturales.

En Monterrey, en más de una ocasión se presentaron tales circunstancias. La primera vez fue a partir del 11 de enero de 1915, cuando los carrancistas evacuaron la ciudad. De esa fecha hasta la designación de nuevas autoridades municipales $-a$ fines del mismo mes- y estatales -16 de febrero- los miembros de la Cámara de Comercio ejercieron y administra. ron los servicios públicos y políticos del ayuntamiento.

A partir de la reconstrucción del aparato estatal revolucionario se debió iniciar una etapa de consolidación y deslinde de funciones políticas, empresariales y militares entre el gobierno, la burguesía regiomontana y èl ejército constitucionalista.

En la práctica, sólo durante la gubernatura de Nicéforo Zambrano -un connotado civil- entre 1917 y 1919, la separación entre el poder civil y militar fue evidente; una variedad de circunstancias nacionales -el constitucionalismo en sí, influido por un poder militar dividido- y regionales -la activa participación de la burguesía citadina-, impidieron la organización y desarrollo de un gobierno civil estatal fuerte, y una burguesía prerrevolucionaria desentendida del poder político.

Durante el carrancismo, el gobierno local nunca logró centralizarse, y su debilidad le impidió controlar a la burguesía urbana e imponer sus condiciones en la puesta en práctica del programa de reformas socioeconómicas del movimiento constitucionalista. 
Hubo una militarización del gobierno civil y la burguesía -pieza clave de esta sociedad-se fortaleció en una poderosa organización indispensable en la toma de decisiones.

Entre mayo de 1915 y diciembre de 1917 se tejieron los matices que posteriormente darían forma y contraste al producto final. La sólida organización empresarial representada en la Cámara Nacional de Comercio hegemonizó toda la actividad económica establecida en Monterrey y regiones circunvecinas, evitando así el acceso a los grandes negocios a la burguesía revolucionaria. La industria pesada, las finanzas, el comercio a gran escala y el Ayuntamiento de Monterrey, fueron predominio absoluto de la burguesía prerrevolucionaria.

La burguesía nacionalista emergida de la revolución se conformó con la adquisición de bienes raíces, antiguas haciendas porfirianas y el comercio interregional, en especial el contrabando proveniente de Estados Unidos. Asimismo, se marginó temporalmente a la añeja burguesía -pero no a sus representantes- de los altos puestos burocráticos, esencialmente las diputaciones federales y estatales, y por supuesto de la gubernatura.

La legislación laboral y la gestoría del estado en las actividades económicas empezó titubeante durante este periodo. La relativa estabilidad social y militar que otorgó el carrancismo en la región -hasta 1920-, propició el repunte paulatino de los negocios en Nuevo León, particularmente en Monterrey.

En suma, las autoridades políticas, civiles y militares posteriores al exilio del procónsul porfirista Bernardo Reyes, comprendieron rápidamente que la burguesía industrial era parte imprescindible -si no esencial- en el aparato estatal.

\section{LA COMUNA EMPRESARIAL}

El 11 de enero de 1915, mientras el grueso de las tropas carrancistas evacuaba la ciudad -e incendiaba tras de sí la estación del ferrocarril-, los socios de la Cámara de Comercio y los cónsules extranjeros acordaron crear un centro urbano de decisiones -llamado por la prensa de la época "comuna empresarial"- en sustitución del gobierno de Antonio I. Villarreal.

Este compromiso entre el cuerpo diplomático y la Cámara de Comercio no era nada extraño. Una buena parte de los socios de origen o bien de as. cendencia extranjera ocupaban cargos diplomáticos. Entre otros se encontra. ban Paul Buchard, ex cónsul y encargado de negocios del imperio alemán desde hacía más de 25 años; Miguel Ferrara, agente consular italiano; John Bertams Sanford, vicecónsul de Gran Bretaña desde 1907; y el mismo presidente de la Cámara, Constantino de Tárnava, quien fungía como cónsul de Bélgica. ${ }^{1}$

Es importante aclarar que la ob-

1 La información sobre comerciantes y empresarios en el cuerpo diplomático de Monterrey fue extraída del Archivo General del Estado de Nuevo León (AGENL), ramos Concluidos, Relaciones Exteriores y Minutas entre 1909-1917. El término "comuna empresarial" fue utilizado por el periódico local La Revolucion entre enero y mayo de 1915. 


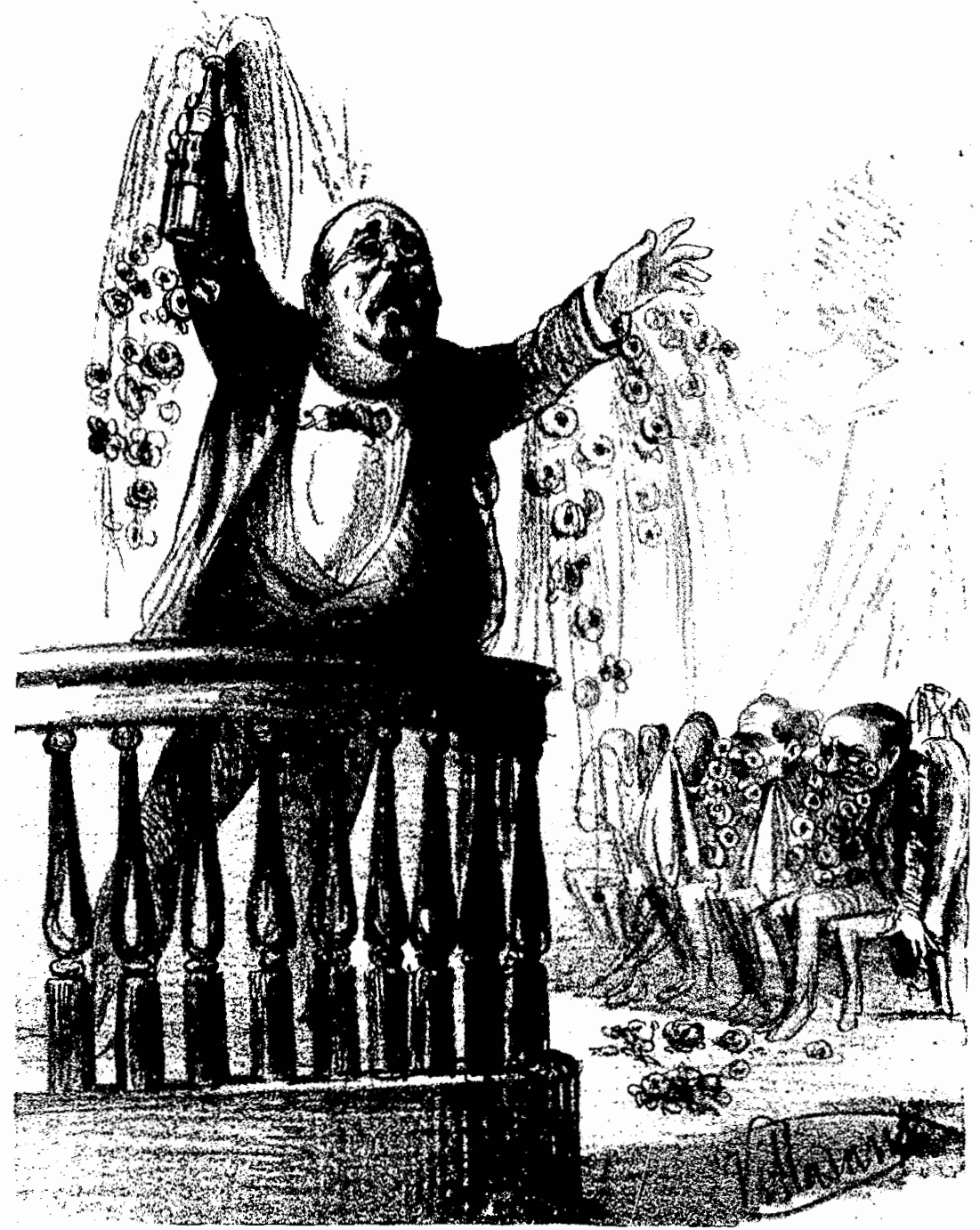

Editork.C.deVillogas 
tención y la reproducción de sus capitales se desarrolló siempre en el ámbito de influencia de la capital nuevoleonesa. Con esto descartamos de antemano que este grupo representara al capital extranjero más allá del espacio diplomático.

De hecho, la Cámara de Comercio desde su refundación -en noviembre de 1911- existió como un órgano parlamentario de asesoría y en ocasiones de decisión -sólo ratificado por el gobernador- en materia política y económica. La participación de la cámara en asuntos públicos otorgó coherencia y peso a las decisiones de una clase social, claramente identificada con el progreso capitalista impulsado durante el porfiriato: la burguesía regiomontana.

Entre los cónsules asistentes a la reunión del 11 de enero destacó uno en especial: Philip C. Hanna. El representante de los intereses norteamericanos en Monterrey era un diplomático de carrera. Nunca penetró en el complicado mundo de los negocios a pesar de ostentar el cargo desde 1899. Pero la gravedad de la situación, motivó su asistencia puntual ese día.

Una vez reunidos, la discusión se centró en dos problemas medulares ralacionados entre sí. El primero de ellos era la ausencia temporal de autoridades encargadas tanto del gobierno municipal de Monterrey como del gobierno estatal.

Ante esta perspectiva, el segundo problema se desprendia inevitablemente de aquél: la gran carestía de artículos de primera necesidad que estaba a punto de provocar agitaciones populares -dentro del espacio urbano- dificiles de control sin au. toridades constituidas. De hecho, ya una parte importante de la población exigía, con "insistencia y en desorden", la venta de los productos de subsistencia. $^{2}$

El primero en proponer una solución viable - tal como lo había previsto De Tárnava- fue el cónsul Hanna. El cónsul norteamericano puso a disposición de la cámara diez bultos de maíz almacenados en el consulado. La propuesta de Hanna fue secundada en acto seguido por dos empresarios más.

El primero de ellos fue el estadunidense B. C. Bailey, gerente de la Compañía de Agua y Drenaje de la ciudad, otorgando cuatro bultos; el otro fue el representante de la Compañía Textil Industrial de Monterrey, quien dispuso 30 bultos más. Las propuestas fueron aceptadas bajo la consigna de "que serían devueltos al tenerse bastante existencia en la plaza". 3 Se optó por venderlos "sin demora" al público en la estación del ferrocarril, mientras se formaban tres comisiones para procurar maíz, pan y carne. ${ }^{4}$

La creación de un órgano coercitivo contra posibles desmanes fue resuelta al extender al comerciante José Videgaray la autoridad -supeditada a la Cámara- para organizar un cuerpo de policía provisional. Una vez puesto el mecanismo en marcha, la asamblea representada por las "fuerzas vivas de la ciudad" se decretó permanente, y pro-

\footnotetext{
2 Mendirichaga, Comercio, 1980 , p. 65.

3 Ibid.

4 Ibid., p. 66.
} 
gramó la próxima sesión a las 17 horas de esa misma tarde. 5

Las comisiones encargadas de adquirir los productos básicos trabajaron arduamente durante los dias siguientes. La distribución de los productos, como fue el caso de la harina y el pan, se llevó a cabo a precio de costo, a través de cuatro expendios que operaban en los puntos cardinales de la capital. El precio galopante de la carne no se pudo controlar, pero la comisión no volvió a preocuparse por la venta de este artículo ya que no afectaba "a la clase menesterosa, pues como es sabido -informó la comisión ante el pleno- ésta no hace gran uso de la misma". 6

Las sesiones continuaron a diario sin interrupción. Pronto los servicios públicos comenzaron a funcionar sin percances bajo la administración empresarial. El día 13 por la mañana, Videgaray informó sobre la labor desarrollada por la policía a su servicios, la cual impidió varios intentos de robo. También se acordó en esa sesión otorgar una contribución voluntaria con el objeto de crear un fondo provisional para el mantenimiento de la policía y las oficinas públicas. ${ }^{7}$

La asamblea permanente fungió del 11 al 15 de enero. Las comisiones para procurar los productos básicos abrieron cuatro expendios ubicados en el puente de San Luisito, el mercado Juárez, el mercado Colón y la bodega del comerciante Prisciliano Elizondo. Si bien la carne se convirtió rápidamente en un artículo de lujo que so-

5 Ibid., p. 66.

6 Ibid., pp. 66-67.

7 lbid., pp. 67-69. lamente una minoría pudo consumir, la cámara logró otorgar un salvoconducto al ganadero Silvano Delgado para que pudiera traer a la ciudad " 20 reses y 400 cabezas de ganado menor que tenía en el cerro del Topo". ${ }^{8}$

Pronto la ciudad volvió a agitarse. La madrugada del 15 de enero el bu. llicio fue causado por el retiro del resto de las tropas carrancistas. Estas sabían de la llegada de los convencionistas esa misma tarde. La asamblea permanente de la cámara -que era ya el verdadero rector de los asuntos públicos de la capital-, optó por organizar una nueva comisión cuyo ob. jetivo era ponerla en contacto con la división Ángeles.

Esta comisión rindió su informe en la tarde del 15 ante la asamblea en pleno, donde explicó haber entablado el diálogo con los convencionistas, quienes informados de la labor desarrollada por la cámara desde el día 11, exigieron que continuaran las cosas como se estaban llevando a cabo, y esperaran la entrada de fuerzas militares suficientes para lograr el completo restablecimiento de la paz y el orden.'

Al término de esa sesión, cuando los socios estaban a punto de retirarse, la ciudad acogió la llegada del grueso de las tropas del general Felipe Ángeles.

LA CONVENCIÓN EN MONTERREY, FERRERO-MAYO DE 1915

El ejército de la Convención se acuarteló en la ciudad sin molestar en lo

8 Ibid., pp. 67-68.

9 Ibid., pp. 68-69. 
más mínimo las actividades desprendidas de la "comuna empresarial". La institución continuó con el control de las entradas y salidas de remesas de productos básicos, así como con su transporte, distribución y finalmente, venta al consumidor.

En un plebiscito celebrado el 24 de enero entre los socios de la cámara, y posteriormente llevado a cabo entre la ciudadanía, las autoridades militares eligieron un nuevo ayuntamiento. José Videgaray, organizador de la policía urbana, resultó electo como alcalde primero. ${ }^{10}$

El evidente apoyo de la cámara a Videgaray se revirtió posteriormente en concesiones políticas a esta institución. Entre ellas destacaron el voto de autorización para la entrega de remesas de maíz que llegaran a la ciudad -con el fin de que siguiera regulándose "el precio de venta"-; ${ }^{11}$ y el anuncio del 25 de enero, cuando Videgaray proporcionó la lista de los colaboradores que integrarían el cabildo municipal, formado por miembros distinguidos de la honorable/Cámara de Comercio. ${ }^{12}$ Los personajes prominentes invitados por Videgaray a formar parte del cabildo fueron, como regidores, Benjamín Buchard, Francisco Zambrano, Carlos Garza Cantú, Adolfo Garza Cantú, Adolfo Garza Zambrano y Eusebio Cueva; y como alcalde suplente, renunciado el mismo día en que fue nombrado, Lorenzo $\mathrm{H}$. Zambrano.

10 Ibid., p. 69.

11 Anuncio de los integrantes del ayuntamiento en el Archivo Municipal de Monterrey (AMM), Actas de Cabildo, 1915, pp. 3-4.

12 Ibid.
Irónicamente, la puesta en práctica del Plan de Ayala por los militares convencionistas -programa aprobado por la Convención Nacional Revolucionaria- reforzó el predominio de la aristocracia empresarial. El 16 de febrero los generales de brigada en el noroeste cumplieron con el artículo $13 \mathrm{del}$ referido Plan, consistente en la elección de un gobernador provisional y comandante militar en cada estado ocupado.

La elección resultó siete votos a uno en contra del general Felipe Ángeles -quien había estado temporalmente en el cargo- a favor de un miembro por demás conocido de la burguesía regiomontana. ${ }^{13}$ Nieto menor por parte del primer matrimonio de don Evaristo Madero y por consiguiente hermano del "apóstol" asesinado, Raúl Madero fue elegido nuevo mandatario estatal.

La elección se llevó a cabo en el lu. joso carro "Ramos Arizpe" -capturado a Antonio I. Villarreal en la batalla del 8 de enero-, que servía como alojamiento al general Ángeles en Monterrey. Aunque en el momento de la designación tres de los generales no se encontraban en ese lugar, tuvieron la precaución de enviar por telegrama el voto a favor de su candidato. ${ }^{14}$

El nuevo gobernador retomó como consejo consultivo a los comerciantes e industriales de la ciudad, al fomentar algunas actividades emanadas de la asamblea permanente de la "comuna empresarial", que concluyó en aquel estado a la entrada de los villistas. Por su parte, para aliviar la

13 AGENL, Militares, 1915, C-1.

14 Ibid. 
crítica situación popular, el gobierno de la Convención adquirió los cuatro expendios donde anteriormente se vendían los artículos de primera necesidad; no sin antes comprometerse a continuar vendiéndolos a precio de costo y a repartirlos en forma gratuita en caso de escasez.

La circular correspondiente al 13 de marzo especificó los mecanismos para la repartición y venta de los susodichos artículos. Se expenderían tarjetas de la Secretaría de Gobernación, donde se registraban el nombre del consumidor, el número de personas que componían su familia y el oficio o empleo a que se dedicaban. ${ }^{15}$

Sin duda el abastecimiento a la ciudad de estos productos agrícolas estaba estrechamente relacionado con la capacidad de producción del agro nuevoleonés. He aquí la preocupación existente en la política agrícola del gobierno de la Convención en Nuevo León, al intentar estabilizar la producción agraria. Ésta se encontraba seriamente mermada por las constantes guerras intestinas, cuya decadencia repercutía en el espacio urbano, donde se provocaban agitaciones populares dificiles de controlar por los efímeros gobiernos revolucionarios.

La creación de instrumentos para canalizar el apoyo al campo tomó prioridad en la política del gobernador Raúl Madero. Tenemos, por ejemplo, la creación, con un capital inicial de 1000000 de pesos, del Banco Refaccionario de Nuevo León, para el fo-

15 AGENL, Circulares: $1910-1917$, circular del 13 de marzo de 1915. mento del comercio y de la pequeña propiedad agrícola e industrial en el estado. ${ }^{16}$

También esta preocupación se vio en el decreto expropiatorio de todas las tierras sin cultivar, para cederlas a aquellas personas que lo solicitasen. El decreto exigía el compromiso a los arrendatarios de tenerlas sembradas a más tardar en un mes en parcelas no mayores de diez hectáreas por individuo. ${ }^{17}$

Otro proyecto fue desempolvado por la legislatura convencionista: la ley de parcelación de comunidades rurales, emitida durante el mandato de Viviano L. Villarreal (1911-1913) salió nuevamente a la luz pública en abril de 1915 . $^{18}$

Sin embargo, las medidas convencionistas tendientes a modificar la estructura agraria quedaron en el papel. Las causas fueron diversas. En primera instancia, la administración villista nunca tuvo el pleno dominio -ni militar ni político- del estado.

Las zonas montañosas del sur de la entidad -donde se concentraba la mayor población agrícola- continua. ron en manos de los carrancistas. En segundo lugar, el tiempo efectivo de ocupación no rebasó los tres meses, dirigiendo sus energías a asuntos de mayor importancia para la causa convencionista en Nuevo Léon como lo fueron la administración militar y el acercamiento con los empresarios regiomontanos. Y finalmente, la escasez de personal técnico que en última ins-

${ }^{16}$ AG ENL, Circulares; C-1910-1917, circulares, marzo-abril de 1915

17 lbid.

18 Ibid. 
tancia llevaría a cabo esta magna em. presa.

Otros decretos con el fin de lograr la pacificación y la estabilidad económica en la entidad fueron: retirar de la circulación los billetes del gobierno de Carranza; amnistía a los carrancistas que estuvieran de acuerdo en deponer sus armas, y la tibia reforma a algunos artículos de la ley hacendaria estatal, que buscó una mayor recaudación a través del aumento de la cuota mensual del "derecho de patente".19

El gobierno del general Raúl Madero también retomó y operó la oficina confiscadora, para adquirir así recursos importantes para el mantenimiento de la administración pública.

Sin embargo, la política anticlerical llevada a efecto anteriormente por la administración carrancista fue desechada, y regresados los bienes incautados al clero católico; lo demuestra el retorno a la biblioteca del Arzobispado -a través de la Biblioteca Pública del Estado- de 4322 volúmenes intervenidos en septiembre de 1914, que junto con numerosas bibliotecas privadas fueron requisadas por pertenecer a "enemigos de la causa". 20

Con la llegada el 13 de marzo del general Francisco Villa a la ciudad, la directiva de la cámara no titubeó en lograr una primera entrevista -a través de Raúl Madero- para extender y reiterar el apoyo existente para la Convención. El caudillo se negó a dialogar ampliamente con la directiva,

19 Ibid.

20 El regreso se hizo el 24 de abril de 1915 por orden directa del gobernador Raúl Madero, AGENL, Minutas: c-1914. por lo que exigió la asistencia de todos los socios al día siguiente en el salón de recepciones del palacio de gobierno.

El día 14 asistieron puntualmente 150 hombres de negocios entre comerciantes, industriales y banqueros acompañados por todos los cónsules acreditados en la capital. Tras la espera por espacio de varios minutos, los asistentes tuvieron el privilegio de ver la entrada de Villa al salón, rodeado, como era de esperarse, de sus más cercanos colaboradores, entre ellos el gobernador Raúl Madero.

Antes de que pudieran los invitados articular alguna palabra, el divisionario acusó acremente a todos los comerciantes de encarecer, acaparar y enriquecerse con la venta de las mercancías. Exigiéndoles, acto seguido, la cantidad de 1000000 de pesos a más tardar para el día 20 de marzo.

El flamante regidor y presidente de la directiva, Carlos Garza Cantú, no pudo más que tartamudear y mostrarse sorprendido por las acusaciones. Este mismo le comentó a Villa que tal exigencia era una tarea que se presentaba poco menos que imposible. La negativa de Garza Cantú no hizo más que enfurecer al caudillo, quien ordenó su aprehensión y su fusilamiento inmediato.

Ante el ambiente tenso que se respiraba, Raúl Madero intercedió por los comerciantes y logró cambiar la decisión de Villa de mantener solamente como rehenes a los miembros de la Junta Directiva, mientras los demás recaudaban la caprichosa cifra. ${ }^{21}$

${ }^{21}$ La entrevista entre empresarios y Fran. 


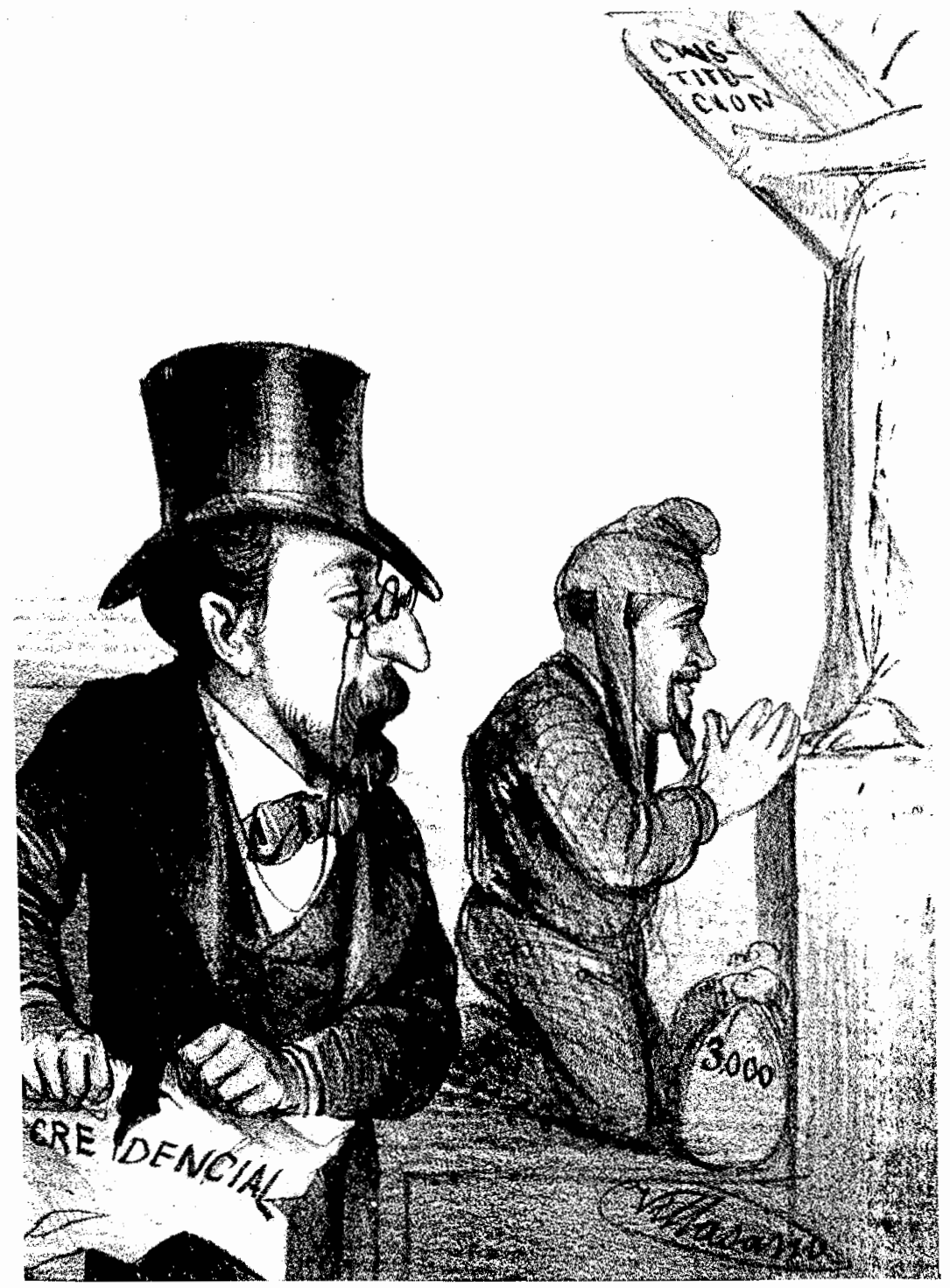

Conservadores que conservan..... Consevadores quo no quieron conservar. 
Al culminar la entrevista, la cámara decidió volver a llamar a sesión permanente a partir del día 15 , hasta contabilizar la posible derrama económica con base en los estados en que se encontraban los diversos negocios. Cuarenta y ocho horas bastaron para entregar al gobierno la lista de los donantes y su cantidad respectiva.

Los primeros donativos empezaron a ser recaudados el 20 de marzo a través del Banco de Nuevo León, donde el principal accionista era la familia Madero. El cierre de la derrama se hizo el 29 del mismo mes. Se recaudaron más de 300000 pesos, que se destinaron a "socorrer al pueblo" a través de la entrega de una cantidad fijada por el banco a casi $\mathbf{8 0 0}$ familias. ${ }^{22}$

Entre los negocios y negociantes mús castigados en relación con la cifra monetaria donada estaban: $\mathbf{M}$. Cantú Treviño y hermano con 50000 pesos; la Fundición número 2 con 15000 pesos; Casa Holck y Cía., 20 000; L. Madero S. de C. con 20000 pesos; José A. Muguerza, Roberto A. Bremer y Cía., La Fama de Nuevo León, José Calderón y Cía, Sucs., con la cantidad de 10000 pesos cada uno, así como Vicente Ferrara, Francisco Zambrano y Valentín Rivero Sucs., con 5000 cada uno. ${ }^{23}$

La designación de José Videgaray como alcalde de Monterrey el 24 de enero, y de Raúl Madero como gobernador el 16 de febrero, sólo marcó el respeto hacia los amos de la ciudad. La "comuna empresarial"

cisco Villa es recreada en las siguientes obras: Aguilar Belden de Garza, Ciudad, 1970; Mendirichaga, Contercio, 1980, pp. 71-72.

22 AGENL, Minutas: 1917, c-27, e-21.

23 Ibid. continuó con sus funciones, entre los meses de enero y mayo de 1915 , como órgano de control y asesoría del aparato estatal convencionista.

La articulación de los jefes militares revolucionarios con los negociantes locales no fue nueva durante la revuelta. El apoyo que pudieran brindar estos últimos siempre fue imprescindible para la buena marcha del poder público local. La experiencia del gobierno radical de 1914 en Nuevo León llevó a replantear la política carrancista a partir de mayo de 1915, y a atenuar notablemente los programas de regeneración social y económica basados en el hostigamiento $y$ deslinde radical de la presencia de la burguesía prerrevolucionaria en el aparato público.

\section{EL CARRANCISMO CONCILIADOR}

\section{La evacuación del gobierno convencionista}

Los dos combates de abril en Celaya, entre el villismo y las tropas de Obregón -donde los primeros no salieron bien librados-, dieron la pauta para el comienzo del repliegue de la punta de lanza convencionista en el noreste. Amagado constantemente en los municipios lejanos a Monterrey por tropas carrancistas volantes de reducido número, el gobierno de Madero volteó la mirada hacia su lugar de origen. ${ }^{24}$

La decisión del 19 de mayo de

24 Ataques carrancistas a los poblados nuevoleoneses durante el gobierno villista en AGENL, Concluidos y Militares, cajas de 1915-1916. 
trasladar su administración -sin haber sido vencida militarmente- a la $\mathrm{Ha}$ cienda de Anhelo, Coahuila, fue sólo un síntoma del desmoronamiento militar y moral del villismo en otras partes del país.

El retiro de la administración pública de Raúl Madero a la hacienda de Anhelo, le permitió permanecer en ese lugar hasta los últimos días de agosto, antes de exiliarse voluntariamente en Estados Unidos. 25

El alejamiento del efímero gobierno de la Convención obligó nuevamente a la capital de Nuevo León -como refurió en su informe el cónsul norteamericano Hanna a Washington-, a quedar "enteramente sin autoridad ni policía que pudiera contrarrestar los desórde. nes y saqueos que se iniciaban". ${ }^{26} \mathrm{La}$ Cámara de Comercio salió de nueva cuenta al ruedo. Mostrando una co. hesión inquebrantable en los momentos de crisis, llamó a asamblea permanente para contrarrestar la situación acéfala por la que atravesaba la administración pública.

El mismo alcalde Videgaray se retiró por miedo a la represión que pudiera sufrir a manos de los carrancistas junto con las tropas del general Raúl Madero. Bajo el amparo de la "comuna empresarial", el capitán primero Juan B. Doria organizó en pocas horas una policía urbana que pronto logró el restablecimiento del orden. ${ }^{27}$ Ante la ausencia de Videgaray, los ne-

25 Covarrubias, Gobernantes, 1979, pp. 124125; Cavazos, Diccionario, 1985, p. 283.

26 "Hanna al gobernador estatal carrancista", julio de 1915, AGENL, Concluidos: 1917, c-8, e-937.

${ }^{27}$ AG ENL, Concluidos: 1917, c-8, e-937. gociantes regiomontanos elevaron a la alcaldía municipal al regidor y socio connotado de la Cámara de Comercio, Francisco Zambrano. Sin em. bargo, sus días como alcalde suplente fueron contados. ${ }^{28}$

\section{ELL FONDO DE AUXIIIO}

Para el 23 de mayo las tropas de la división norestense volvían a pasearse por las calles citadinas de Monterrey. Pero ahora la lección fue asimilada. EI joven grupo en el poder se retractó de iniciar otra ola represiva contra la burguesía urbana. La revolución no pudo desprender a los amos de la economía regiomontana de los asuntos públicos.

Éstos, para su buena marcha, requerían de la mejor convivencia con la fuente de riqueza y de recursos que a final de cuentas sostendrían el aparato político. En pocas palabras, la revolución dejó intacta a esta elite porfiriana que tuvo, sin embargo, que adaptarse a los nuevos requerimientos del embrionario Estado revolucionario.

En Monterrey las autoridades fueron reinstaladas y se nombró un gobierno interino cuya jefatura recayó en el general Idelfonso Vázquez. De inmediato la administración carrancista pidió el apoyo de los miembros de la Cámara de Comercio para hacer frente a una de las hambrunas jamás registradas en la capital.

A principios de junio, la Cámara de Comercio, las autoridades militares y el cuerpo diplomático se vieron

28 El Porvenir, Monterrey 30 de noviembre de 1921 , p. 1. 
obligados a sesionar conjuntamente, ante el miedo que podían representar los brotes de desorden que aparecían cada vez con mayor frecuencia en todos los rumbos de la ciudad.

El pueblo se dedicó a buscar y saquear, en los pequeños y grandes almacenes, los productos básicos que notoriamente escaseaban como resultado de casi cinco años de revueltas intestinas.

El dictamen de la reunión fue unánime. Se creó un Fondo de Auxilio con el objeto de vender estos artículos a precios más bajos que el de costo; absorbían las pérdidas, momentáneamente, los grandes comerciantes, no sin antes arrancar el consentimiento a las nuevas autoridades para su reembolso una vez saneado el erario municipal. Esto se haría a través de diversos mecanismos contemplados, como la rebaja de impuestos o bien la entrega líquida de la deuda. ${ }^{29}$

El consulado norteamericano también se comprometió a absorber temporalmente el precio de costo y transporte de una importante remesa de maíz y frijol, facilitada por la Cruz Roja norteamericana al Fondo de Auxilio. ${ }^{30}$ Así pues, la experiencia adquirida por la "comuna empresarial" y eí consulado estadunidense, guiaron a los todavía inexpertos representantes públicos a aceitar un aparato cuya maquinaria había sido ensayada con anterioridad.

Al mismo tiempo que los miembros activos de la cámara distribuían en sus

29 AGENL, Concluidos: $1916, \mathrm{c}-1$.

$30 \mathrm{Ibid}$ casas comerciales los productos básicos a un precio irrisorio, el cónsul Hanna y la Cruz Roja texana repartían a la población "más de 3000 tarjetas de auxilio -que representaba a no menos de 20000 almas-, para suministrar gratuitamente dos veces por semana raciones de maíz y frijol". ${ }^{31}$ La cuesta del hambre fue rebasada hacia el mes de julio.

Al concluir las tareas desarrolladas poŕ la cámara, el informe final arrojó una pérdida para los socios de 17797 pesos; además se adeudaba a la Cruz Roja norteamericana 9 191, por suministro de los productos de frijol y maíz a la ciudad, responsabilizándose en ese momento el gobierno de Vázquez a cubrir esta última cantidad. ${ }^{32}$

\section{EN BUSCA DE LA CONCILIACIÓN}

La radicalización de la revolución carrancista llegó hasta donde los recursos económicos le permitieron. Las tropas que penetraron en mayo a Monterrey tuvieron que ser auxiliadas a través de préstamos otorgados por los principales banqueros regiomontanos. El 1 de junio los Milmo no sólo subsanaron la bancarrota manifiesta del ayuntamiento, sino también facilitaron los haberes de las tropas del general Raúl Vicente Dávila. ${ }^{33}$

En una circular hecha pública el

31 Ibid.

32 Mendirichaga, Comercio, 1980, pp. 73-75.

33 Préstamo de 10000 pesos por parte de los Milmo al ayuntamiento, así como los haberes de las tropas de Dávila. Mendirichaga, Comercio, 1980, p. 75. 
29 de junio, el gobierno pidió de nuevo el salvavidas a los comerciantes e industriales, al crear un "Impuesto temporal para la reorganización de los servicios públicos" de $50 \%$ sobre las contribuciones ordinarias. ${ }^{34}$

Unos días antes, el 15 de junio, un experimentado militar de carrera durante el porfiriato, incorporado al movimiento armado con Pablo González Garza desde 1910, el general Pablo A. de la Garza -en su papel de relevo en la gubernatura nuevoleonesa-clausuró de manera definitiva la oficina de incautación y decomisación de fincas de los enemigos de la causa. ${ }^{35}$

Los trámites para recobrar los bienes intervenidos fueron simples. Se requería urgentemente de recursos y quien los tuviera a la mano y estuviera dispuesto a llegar a un arreglo, no encontraría ningún problema. Los requisitos se especificaron: "Se pide la documentación del verdadero dueño; el previo pago de los gastos de administración; y el valor de las cosechas -en el caso de las fincas agrícolas- por producirse."36

La decisión del gobernador De la Garza se adelantó por varios meses -ocho en total-a la prohibición nacional de intervención de bienes y a la orden de devolución de bienes ya confiscados, a sus dueños originales. El respeto a las propiedades particulares fue piedra angular del programa constitucionalista, esencialmente a partir de 1916.

En una carta fechada en junio de

34 "Circular del 29 de junio de 1915", AGENL, Circulares: 1910-1917.

${ }^{35}$ AGENL, Concluidos: 1914-1916.

36 AGNL, Concluidos: 1914, c-4.
1916 de Venustiano Carranza al general Jacinto B. Treviño -jefe del cuerpo del ejército del noreste-, aquél explicó las razones de la desaparición de las oficinas de incautación, debido a "la ineficiencia de las mismas y las dificultades que nos ha originado por la falta de honradez de los miembros que las integran". ${ }^{37}$

También las comisiones reguladoras de bienes públicos desaparecieron, a excepción de la del henequén y la del algodón.

El rencor igualmente fue guardado bajo llave y olvidado. En una convocatoria fechada el 18 de junio, el gobierno preconstitucional invitó a todos aquellos "que hayan servido antes a cualquier administración pública y sean honrados", previa carta al gobernador, a solicitar de nuevo su ingreso.38

Lentamente la capital nuevoleonesa recobró su sitio como centro hegemónico de irradiación de poder. De la Garza -gobernador de junio de 1915 a mayo de 1917-se aplicó rápidamente a crear "cuerpos regionales, sostenidos por el gobierno estatal" cuyos jefes natos asumian la primera autoridad política del lugar. ${ }^{39}$ Los cuerpos de policía rural, como fue el caso del municipio de Dr. Coss -con 18 hombres-, se alimentaron con vecinos del poblado "sin percibir sueldo, salvo la exención del pago de contribuciones".40

37 Hernández Chávez, "Militares", 1984, p. 200.

38 "Convocatoria del 18 de junio de 1915", AGENI, Circulares: 1910-1917.

39 "Informe del gobernador al pueblo de Nuevo León, del 16 de septiembre de 1915", AGENL, S. P.

${ }^{10} \mathrm{Ibid}$. 
La extensa campaña de reinstalación de autoridades municipales durante 1915 bajo el lema de la honradez -aunque hubieran participado como defensores del antiguo régimen porfiriano-, se realizó por medio del hermano del gobernador y jefe de la brigada Nuevo León, coronel Diódoro de la Garza. ${ }^{41}$

La consolidación de las autoridades carrancistas instaladas en Nuevo León se legitimó en la circular del gobierno general, el 24 de noviembre de 1915. Ésta prohibía, hasta que se restableciera el orden constitucional, la fundación de agrupaciones políticas "cuyas tendencias casi siempre" no tenían "otro fin que trabajar en favor" de los caciques regionales. ${ }^{42}$ Por lo tanto, se suspendian las convocatorias a elecciones generales y locales, tal y como lo preveía el actualizado artículo 4 del plan revolucionario de Guadalupe.

Astutamente, los carrancistas no permitieron la libre elección de representantes estatales y municipales hasta agosto de 1917. Los jefes militares preconstitucionales en Nuevo León eran una copia burda de los viejos burócratas porfirianos. El mismo gobernador Pablo A. de la Garza -rico terrateniente ganadero- había servido al extinto ejército federal. De hecho, para fines de 1915, en todo el país eran pocos los militares radicales o de origen social precario con posiciones de mando importantes.

Es verídica la afirmación de que el alto mando carrancista del noreste

41 AG ENL, Minutas: $1915, c-659$.

$\$ 2$ "Circular del gobierno federal del 24 de noviembre de 1915", AGENL, Circulares: 19101917. también destacó por su participación en negocios jugosos. Los nuevos hombres de empresa encontraron con eficacia la forma no sólo de amasar fortunas personales, sino de mantenerse a flote, militar y políticamente. Los ejemplos son numerosos.

El general Jacinto B. Treviño, jefe del cuerpo del ejército del noreste, y por lo tanto el más alto en la jerarquía militar de la región, fue presidente de la Comisión Reguladora de Algodón en la región lagunera, donde se producía 90\% del algodón del país. ${ }^{43} \mathrm{Al}$ ser sustituido por Francisco Murguía en 1916, los negocios del noreste encontraron un empresario más audaz y astuto. ${ }^{44}$

Lo mismo podría decirse del personaje civil de mayor confianza de Carranza en la región, Nicéforo Zam. brano. Fue elegido como diputado federal en noviembre de 1916 y, posteriormente, electo gobernador en julio de 1917. Zambrano no sólo estuvo al lado de Venustiano Carranza cuando éste entró al Congreso Constituyente en México, el día de la protesta de la nueva Constitución Política del país en febrero de 1917, sino también fi. guró en la localidad como un prominente terrateniente en Coahuila y Nuevo León y como un audaz acaparador del espacio urbano en Monterrey. También era miembro distinguido de la Cámara Nacional de Comercio. 45

Pero lo más representativo fue su

43 Hernández Chávez, “Militares”, 1984, pp. 203-204.

14 Ibid., pp. 206-208.

15 Datos recopilados en Agknt, Concluidos y Minutas, 1911-1920; Cavazos, Dicclonario, 1985, p. 527. 


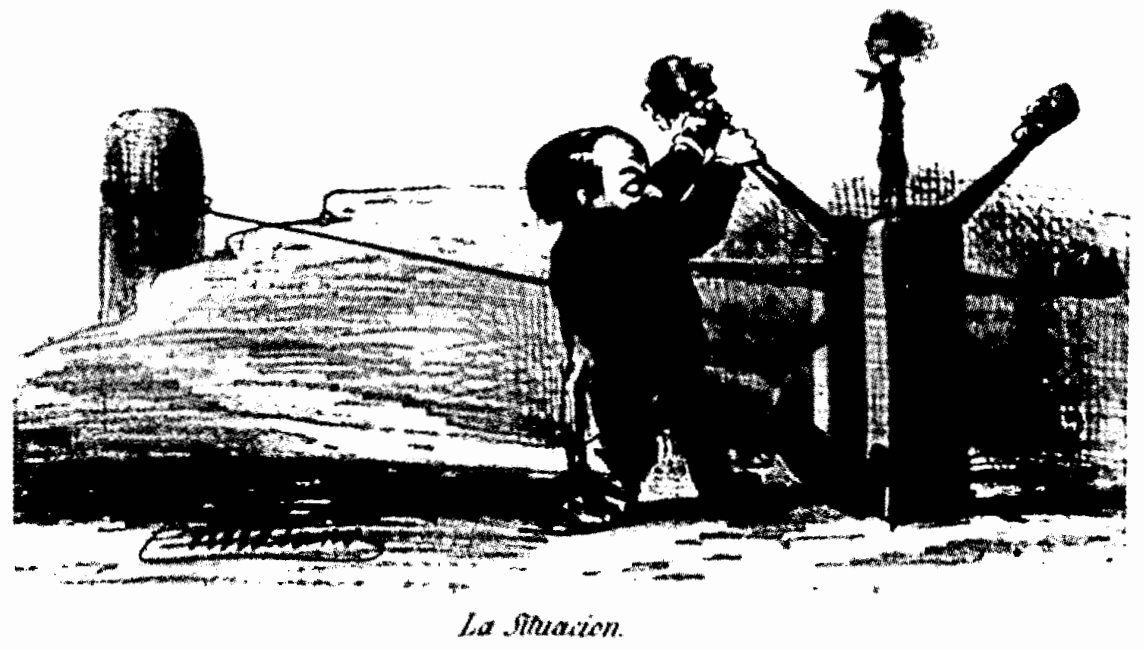

candidatura al cargo de ejecutivo del estado lanzada por el Partido Constitucional Progresista, que se formó precipitadamente en vísperas de las elecciones. El partido fue sostenido por la burguesía citadina cuidándose de no aparecer en primer plano. ${ }^{46} \mathrm{Al}$ igual que el presidente del partido, Jerónimo Siller, Nicéforo Zambrano representó la alianza de la burguesía con los revolucionarios locales más conservadores.

Nicéforo Zambrano fue el primer candidato sólido de la burguesía regio-

46 El Porvenir, Monterrey, 8 de marzo de 1923. Centro de Estudios de Historia de México (CONDUmex), Archivo de Venustiano Carranza (AVC): fondo XXI, carpeta-2, documento 145; Cavazos, Diccionàrio, 1985, p. 452. montana a un alto puesto público por elección popular en la etapa constitucional.

El gobierno constitucional de Zambrano se inició el 30 de julio de 1917 , en medio de una escasez de cereales crónica, un repunte titubeante de los negocios urbanos, una agricultura y ganadería en ruinas, y una hacienda estatal exhausta, por lo que los métodos estatales de recaudación fiscal buscaron siempre, hasta 1919 -con base en experiencias anteriores-, la vía menos espinosa con la burguesía industrial sobreviviente del porfiriato. ${ }^{47}$

El 16 de diciembre de 1917, los tres poderes públicos de Nuevo León

47 Flores Torres, Burguesia, 1991, pp. 165199. 
protestaron frente a la nueva Constitución Política del Estado, cuyas bases esenciales eran emanadas de la Constitución General elaborada en la ciudad de Querétaro. El ambiente de gran jolgorio capturó las silbatinas de los talleres y fábricas, y "el repique de las campanas de la iglesia en la ciudad". ${ }^{48}$

La aparente culminación de las inquietudes de los grupos revolucionarios vencedores al ser promulgada la nueva carta general, fue sólo el inicio de un largo trayecto -todavía violento- de reacomodo y negociación entre las fuerzas sociales desatadas durante la confrontación.

La Constitución estatal, que em. pezó a regir a partir del 1 de enero de 1918 , otorgó la pauta donde la confrontación entre capital y trabajo remarcó fuertemente las características del periodo siguiente. La burguesía industrial volvió su mirada al interior de sus talleres, comprendiendo que el enemigo principal no se encontraba en los altos mandos de la jerarquía militar constitucionalista -ahora más que nunca interesados en mantener el statu quo-sino en los que habitaban diariamente sus fábricas: los obreros.

\section{CONCIUSIONES}

El ala radical de la revolución representada por los villistas y los zapatistas fue considerablemente debilitada militar y políticamente, a partir de 1915 ,

48 El programa oficial del 16 de diciembre fue expuesto por el periódico El Liberal, Monterrey, 10 de diciembre de 1917. Referencias al ambiente que privó en esa ocasión, AGENL, Minutas: 1917. por los constitucionalistas, más conservadores. El programa constitucional, aplicado en Monterrey a partir de mayo de 1915, presuponía la conservación de la estructura de propiedad existente y el respeto escrupuloso de la propiedad norteamericana.

Entre mayo de 1915 y diciembre de 1917, el mando constitucionalista en Nuevo León no consolidó medidas que otorgaran a la acción gubernamental un papel estratégico en la regulación de la economía. Todo lo contrario, en situaciones de emergencia, el aparato estatal requirió cada vez más de la experiencia y asesoría en asuntos públicos de la "comuna empresarial".

La Cámara de Comercio de Monterrey constituyó una barrera inexpugnable para toda escalada expropiatoria gubernamental tendiente a alterar la continuidad de la burguesía regiomontana. Por ejemplo, las decisiones de crear comisiones reguladoras del comercio -que tienen su origen local en el porfiriato-destinadas a controlar el abasto, el alza inmoderada de precios, la especulación y la carestía, que. daron bajo pleno dominio de la burguesía citadina.

Los fondos de auxilio a la población para el abasto y distribución de los productos primarios, y los continuos préstamos a los gobiernos carrancistas -por parte de la burguesía prerrevolucionaria-, crearon una vasta red de poder empresarial que condiciono, en gran medida, la aplicabilidad del programa de reforma social y económica del constitucionalismo.

Sin embargo, el aparato estatal revolucionario reafirmó su legitimidad a través de una lenta pero progresiva incursión como nuevo conciliador de los 
problemas laborales. Paralelamente, su papel más radical y decisivo, la acción de incautación de bienes a los enemigos de la revolución, pasó a un segundo plano en la entidad.

El alto mando carrancista en el estado no volvió a aplicar de manera importante esta prerrogativa que le otorgó la revolución. Al parecer, fue todo lo contrario. No hubo mayor alteración en la nómina de los principales propietarios nuevoleoneses; in. clusive se revirtió el proceso al trasladarse drásticamente por el gobierno un sinnúmero de bienes administrativos, provisionalmente, a sus dueños originales.

La incorporación a la alta esfera económica y social por parte de los revolucionarios -militares y civiles- carrancistas destacados en el noreste, es por cierto bastante notoria. Las actividades económicas más codiciadas fue. ron la adquisición de tierras, el comercio, la especulación y el contrabando. Las finanzas, el comercio a gran escala y la industria pesada continuaron como exclusivos de la burguesía regiomontana. Esta en ningún momento permitió la permeabilidad social hacia estos rubros, por demás vanguardistas, del desarrollo capitalista.
El problema obrero pasó a ser un asunto vital en el progresivo debilita. miento del régimen carrancista en el estado. A partir de 1918, la burguesía regiomontana se enfrentó a un vigoroso movimiento laboral que había permanecido hasta cierto punto pasivo y al margen de la convulsión social. Ahora, salía de su acorralamiento para transitar por la zigzagueante historia de México.

\section{Bibliografía}

- Aguilar Belden de Garza, Sara, Una ciudad y dos familias, Editorial Jus, México, 1970.

-Cavazos, Israel, Diccionario biográfico de Nuevo León, 2 vols., Universidad Autónoma de Nuevo León, Monterrey, 1985.

-Covarrubias, Ricardo, Gobernantes de Nuevo Le6n, 1582-1979, Gobiemo del Estado de Nuevo León, Monterrey, 1979.

-Flores Torres, Óscar, Burguesía, militares y movimiento obrero en Monte. rrey, 1909-1923, Universidad Autónoma de Nuevo León, Monterrey, 1991.

-Hemández Chávez, Alicia, "Militares y negocios en la revolución mexicana", Historia Mexicana, vol. xxxiv, núm. 2 (134), octubre-diciembre 1984.

-Mendirichaga, Rodrigo, 100 años de comercio en Monterrey, Cámara de Comercio, Monterrey, 1980. 